\title{
Seismic Behavior of RC Intze Water Tank under Various Zone and Soil Condition
}

\author{
Rakesh Yadav, Trilok Gupta, Ravi S. Sharma
}

\begin{abstract}
R C$ intze water tanks are constructed for storage and suppling of water through a certain height with adequate pressure of water distribution. Many overhead water tanks affected due to certainty like earthquake that can induce large lateral forces. So, there is a necessity to Understand and examine the behavior of intze tank supported on framing in context to different soil types under the seismic forces. This paper evaluates the experimental output of seismic analysis that compares shear and moments at base for different seismic zone $(I I, I I I, I V, V)$ in different type of soil conditions.
\end{abstract}

Keywords: Intze water tank, Seismic analysis, Base shear, Base moment.

\section{INTRODUCTION}

W ater supply plays a portal vote day to day life and adequate storage is highly desirable, is proportional to increase in population, requirement for drinking water has increased and also due to a shortage of electricity at various regions of India, it is not possible to supply water through pumps at peak time. So, at such scenario elevated water tanks happen to vital part of life [1]. Earthquakes affected several tanks in past that can induce large horizontal and overturning forces in elevated water tanks. The elevated water tank damaged due to a large mass concentrated at the top with the relatively slender supporting system [2-3]. Water tanks can distress in different situations like inaccurate structural configuration design, poor materials quality and workmanship, corrosion of reinforcement, wind forces and earthquake [4]

\section{LITERATURE REVIEW}

Harsha et al. [7] analyzed and designed Intze water tank by considering the quake forces as per IS 3370-2009 and draft code IS 1893(Part-2): 2002 with two mass model i.e. impulsive model and convective model. They observed that time period; base shear and moment determined by convective mode of vibration was greater as compared to the impulsive mode of vibration. Shear and moment at base by two mass model modes were obtained $36 \%$ and $41 \%$ respectively as compared to the lumped mass model method.

Revised Manuscript Received on March 15, 2020.

Rakesh Yadav, Techno India NJR Institute of Technology, Udaipur Rajasthan, India. E-mail:rakeshyadav1927@gmail.com

Trilok Gupta, Maharana Pratap University of Agriculture and Technology University in Udaipur, Rajasthan, India.

Ravi S Sharma, Maharana Pratap University of Agriculture and Technology University in Udaipur, Rajasthan, India.
Livaoglu and Dogangun [8] they used finite elements model with the frame type and shaft type supporting system. It has been observed that the supporting system affect the sloshing displacement as compared to shaft type system. It was found that the displacement decreased $83 \%$ for frame type supporting system. However, $12 \%$ displacement decreased, when the shaft type supporting system is used.

Shakib et al. [9] analyzed RC elevated water tanks, having capacity of 900 cum and at a height of staging 25, 32 and 39 $\mathrm{m}$. It is assumed that concrete behaves nonlinearly. So, study entailed the shear and moment at base increases in the range between 10-20 \%, and 13-32 \% respectively. Also, displacement and hydrodynamic pressure increases in the range between 10-15\% and 8-9\%, respectively.

Vyankatesh and Varsha [10] analyzed the circular Intze tank supported on RC frame staging and shaft staging at different staging height for different capacities and seismic zones for IS 1893 (Part-II):2014, is derived the increase in tank capacity for the different seismic zone and also base moment supported on frame staging was less as compared to shaft staging.

\section{MATHODOLOGY}

It must be ensured that the water tank design is capable to withstand certainty like earthquake loading, which varies with an increase in seismic zones.

\subsection{Methods of seismic analysis}

Mainly two different types of design analysis are as follows.

\subsubsection{Equivalent static analysis:}

Statistical approach can be efficiently appeal to elevated water tank. It is dependent on representation of seismic load in the form of identical static loads. Approximate in context to tank is vital and without any degradation, in accuracy estimate, a single degree of freedom is sufficient.

$$
\mathrm{K}=\mathrm{P} / \Delta
$$

Where

$\mathrm{K}=$ Lateral Stiffness of staging

$\mathrm{P}=$ Applied lateral force

$\Delta=$ Deflection in $\mathrm{mm}$

\subsubsection{Dynamic analysis:}

It is very hard to analyse the dynamic nature of elevated water tank. Due to static behaviour of tank, predictions can hardly be done. Elevated water tank having liquid with free surfaceis related to motion of natural calamity like earthquake and the direction of motion result in acceleration of the tank wall and liquid. 


\section{Seismic Behavior of RC Intze Water Tank under Various Zone and Soil Condition}

The liquid in the tank at lower region acts such a man that is stacked to wall. This is called impulsive mass of liquid $\left(\mathrm{m}_{\mathrm{i}}\right)$. Whereas liquid in tank at upper region is termed as convective mass of liquid $\left(\mathrm{m}_{\mathrm{c}}\right)$ due to sloshing motion.

\section{Shear at Base}

Impulsive Phase, $V_{i}=\left(A_{h}\right)_{i}\left(m_{i}+m_{s}\right) g$

Convective Phase $V_{c}=\left(A_{h}\right)_{c} m_{c} g$

\section{Moment at Base}

Impulsive Phase, $\mathrm{M}_{\mathrm{i}}{ }^{*}=\left(\mathrm{A}_{\mathrm{h}}\right)_{\mathrm{i}}\left[\mathrm{m}_{\mathrm{i}}\left(\mathrm{h}_{\mathrm{i}}{ }^{*}+\mathrm{h}_{\mathrm{s}}\right)+\mathrm{m}_{\mathrm{s}} \mathrm{h}_{\mathrm{cg}}\right] \mathrm{g}$

Convective Phase, $\mathrm{M}_{\mathrm{c}}{ }^{*}=\mathrm{A}_{\mathrm{hc}} \mathrm{m}_{\mathrm{c}}\left(\mathrm{h}_{\mathrm{cg}}+\mathrm{h}_{\mathrm{s}}\right) \mathrm{g}$

Where,

$\mathrm{A}_{\mathrm{h}}=$ Design seismic horizontal seismic coefficient.

$\mathrm{h}_{\mathrm{s}}=$ Structural staging height.

$\mathrm{h}_{\mathrm{cg}}=$ Height from C.G. of empty container of tank

\subsection{Study Parameters}

Details of Constants data, dimensions of various elements, and detail of tank geometry are given in Table 1 and Table 2.

Table I: Constants data for intze water tank

\begin{tabular}{|c|l|c|}
\hline S.No & \multicolumn{1}{|c|}{ Constants } & Value \\
\hline 1 & Volume of liquid & $260 \mathrm{~m}^{3}$ \\
\hline 2 & Materials & $\mathrm{M}-30 \& \mathrm{Fe} 415$ \\
\hline 3 & Unit weight (RCC) & $25.01 \mathrm{kN} / \mathrm{m} 3$ \\
\hline 4 & $\mathrm{E}_{\mathrm{c}}$ & $2.73 \times 10^{7} \mathrm{kN} / \mathrm{m}^{2}$ \\
\hline 5 & Seismic Zone (Z) & II, III, IV, V \\
\hline 6 & (I) & 1.5 \\
\hline 7 & R & $2.5,3$ \\
\hline 8 & Soil Type & All \\
\hline
\end{tabular}

Table II: Various component for intze water tank

\begin{tabular}{|l|l|c|}
\hline S.No & \multicolumn{1}{|c|}{ Elements } & Size $(\mathbf{m m})$ \\
\hline 1 & Thickness of Dome at Top & 125 \\
\hline 2 & Dimension of Ring beam (at top) & $300 \times 450$ \\
\hline 3 & Thickness of RC wall (Cylindrical) & 220 \\
\hline 4 & Dimensions of Ring beam (at bottom) & $450 \times 450$ \\
\hline 5 & Circular Main Ring Beam & $600 \times 600$ \\
\hline 6 & Thickness Dome (at Bottom) & 220 \\
\hline 7 & Thickness of Dome (Conical) & 300 \\
\hline 8 & Sizes of Bracings & $450 \times 450$ \\
\hline 9 & Diameter of Columns & 600 \\
\hline
\end{tabular}

In this research, results of elevated intze water tank carried out by using software i.e. STAAD Pro and MS excel, to determine the various forces such as base shear and base moments have been determined.

Seismic parameters have been determined for various type soil seismic zones, as consideration of single mass model according IS 1893 (Part-1) 2002 \& two mass model as per IS 1893 (Part-2) 2014. Empty tank condition was simulating for above consideration.

\section{RESULTS AND DISCUSSIONS}

\subsection{Various Seismic Zone effect on Base Shear}

Figure 1 and 2 represents the range of variation in base shear for different zones and it was observed that the shear at base increased as increases of zone factor. From Figure 1 it was found that the shear at base increased by $60 \%, 143 \%$ \& $263 \%$ for seismic zone III, IV \& V as compared to zone II for IS 1893 (Part-I): 2002 respectively for empty tank condition. Also, it is observed from the Figure 2 that the shear at base increased by $59 \%, 139 \%$ \& $259 \%$ for seismic zone III, IV \& $\mathrm{V}$ as compared to zone II for IS 1893 (Part-II): 2014 respectively for empty tank condition.

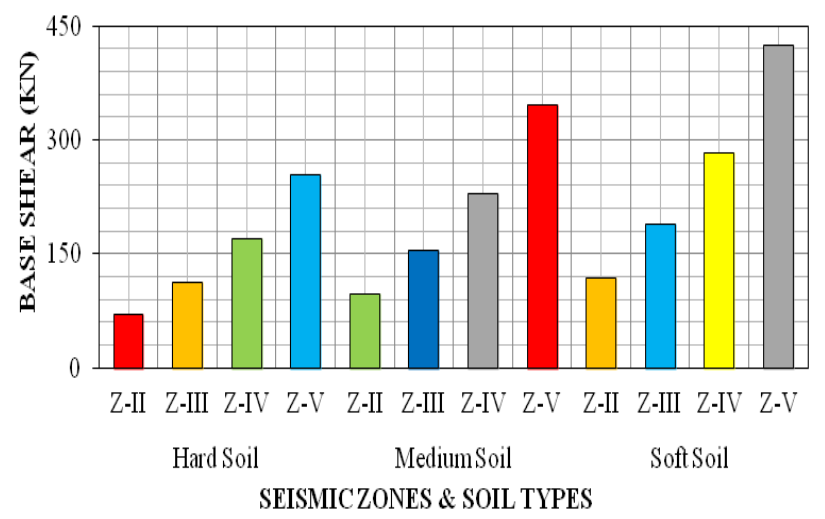

Fig. 1. Comparison of base shear in various seismic zone and soil as per IS 1893(Part-I): 2002 for empty tank condition.

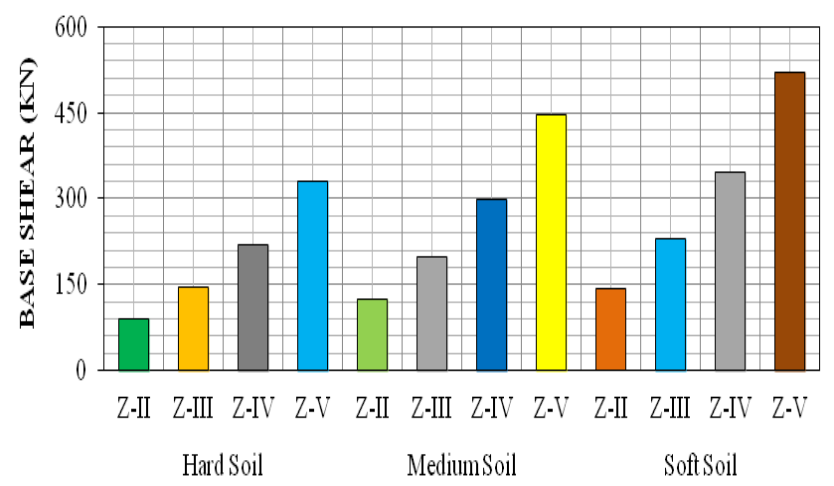

SEISMICZONES \& SOIL TYPES

Fig. 2. Comparison of base shear in various seismic zone and soil as per IS 1893(Part-II): 2014 for empty tank condition.

\subsection{Various types of soil effect on Base Shear}

Figure 1 and 2 gives range of variation in base shear for different soil types and it was observed that the shear at base increased when soil having low bearing strength (i.e. Soft soil) as per IS 1893 (Part-I): 2002 and IS 1893 (Part-II): 2014 for tank empty condition. Also, it is found from the Figure 1 that the base shear increased by $36 \%$ and $67 \%$ for medium and low strength soil as compared to the high strength soil (hard strata) as per IS 1893 (Part-I) 2002 for all seismic zones for empty tank condition. Figure 2 revealed that the base shear increased by $36 \%$ and $67 \%$ for medium and low strength soil as compared to the high strength soil (hard strata) as per IS 1893 (Part-II) 2014 for all seismic zones for empty tank condition. 


\subsection{Various Seismic Zone effect on Base Moment}

Figure 3 and 4 represents the deviation of the base moment for various seismic zones and it was observed that the moment at base increased as increases of zone factor.

Figure 3 shows that the moment at base increased by $60 \%$, $140 \%, 260 \%$ for zone of III, IV \& V as compared to II zone for IS 1893 (Part-I): 2002 respectively for empty tank condition. It was observed from Figure 4 that the moment at base increased by $59 \%, 139 \%, 259 \%$ for zone of III, IV \& V as compared to II zone for IS 1893 (Part-II): 2014 respectively for empty tank condition.

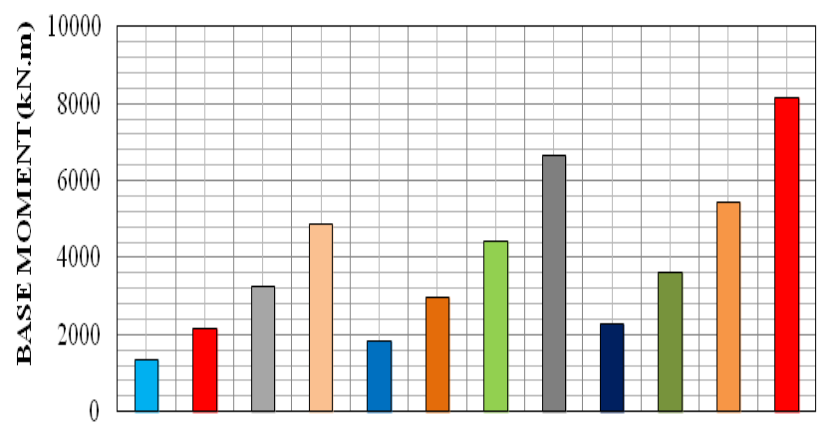

Z-II Z-III Z-IV Z-V Z-II Z-III Z-IV Z-V Z-II Z-III Z-IV Z-V Hard Soil Mediumsoil Sots Soil

SEISMICZONES \& SOIL TYPES

Fig. 3. Comparison of base moment in various seismic zone and soil as per IS 1893(Part-I): 2002 for empty tank condition.

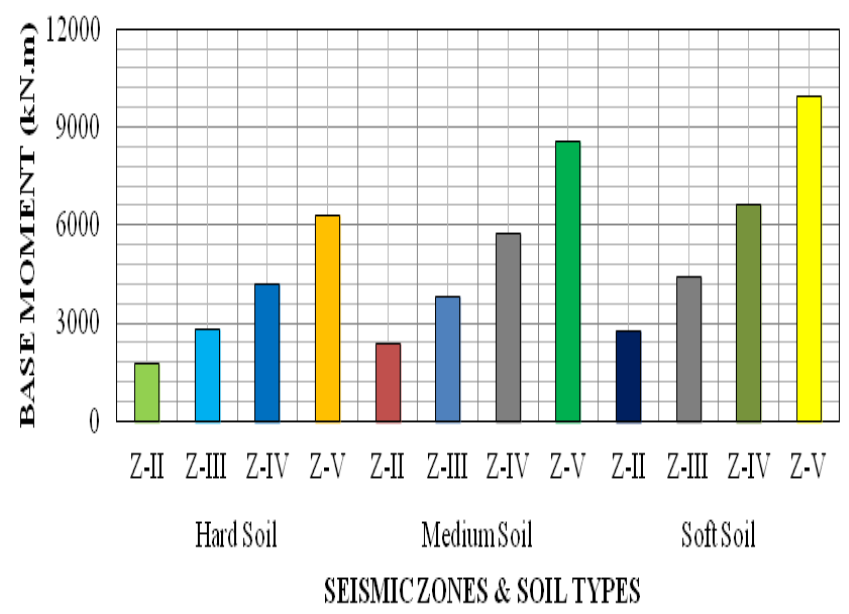

Fig. 4. Comparison of base moment in various seismic zone and soil as per IS 1893(Part-II): 2014 for empty tank condition.

\subsection{Various types of soil effect on Base Shear}

Figure 3 and 4 shows the deviation of the base moment for different soil types. It was observed from Figure 3 that the base moment increased by $36 \%$ and $67 \%$ for soil having medium and low strength soil as compared to the high strength soil (hard strata) as per IS 1893 (Part-I) 2002 for all seismic zones for empty tank condition. Figure 4 revealed that the base moment increased by $36 \%$ and $67 \%$ for soil medium and soft soil as compared to the hard soil as per IS 1893 (Part-II) 2014 for all seismic zones for empty tank condition.

\section{CONCLUSION}

According to the analytical results and discussions, the following conclusion can be taken as:

- The shear and moment at base increased with increasing design horizontal seismic coefficient $\left(\boldsymbol{\alpha}_{\mathrm{h}}\right)$.

- Shear and moment at base increased in the range of 59\%-301\% for seismic zone III, IV \& V as compared to seismic zone II respectively for empty tank condition.

Soil having low bearing strength is much severe than medium and high bearing strength soil. Base shear and base moment increased by $36 \%$ and $67 \%$ for medium and soft soil as compared to the high bearing strength of soil as per IS 1893 (Part-I) 2002 IS 1893 (Part-II) 2014 for all seismic zones for empty tank condition.

\section{REFERENCES}

1. G. Madhukar and M. Madhuri, "Seismic Performance of Circular Elevated Water with Framed Staging”, International Journal of advanced research in Engineering and Technology, 4(4), 2013, 159-167.

2. M. S. Mhetre and G. R. Patil, "Analysis of Elevated Water Storage Structure Using Different Staging System", IOSR Journal of Mechanical and Civil Engineering (IOSR-JMCE), 2(6), 2015, 21-32.

3. S.K. Jain and S.U. Sajjad, "A Review of the requirement in Indian codes for a seismic design of Elevated water tanks", The Bridge and Structural Engineering, 12(1), 1993, 1-15.

4. K Harsha, K. S. K Reddy and S.K Kala, "Seismic Analysis and Design of Intze Type Water tank", International Journal of Science Technology and Industrial Engineering, 2(3), 2015, 11-24.

5. O. R Jaiswal. and S. K Jain, "Modified Proposed Provisions for a Seismic Design of Liquid Storage Tanks: Part II-Commentary and Examples", Journal of Structural Engineering, 32(4), 2005, 297-310.

6. IS 1893 (Part-2) "Criteria for Earthquake Resistant Design of Structures Part 2 Liquid Retaining Tanks", Bureau of Indian Standards, New Delhi, 2014.

7. J. Lakhankiya and H. J Shah, "A Parametric Study of an Intze Tank Supported on Different Staging”, International Journal for Science Research in Engineering and development, 3(9), 2015, 1108-1112.

8. R. Livaoglu and A Dogangün, "Effect of Foundation Embedment on Seismic Behavior of Elevated Tanks considering Fluid- Structure-Soil Interaction", First International Conference on Seismology and Earthquake Engineering (SEE), 27(1), 2007, 855-863.

9. H. Shakib, F Omidinasab, and M. T Ahmadi, "Seismic Demand Evaluation of Elevated Reinforced Concrete Water Tanks", International Journal of Civil Engineering, 8(3), 2010, 204-220.

10. K. Vyankatesh and T. Varsha, "Comparative study on dynamic analysis of elevated water tank frame staging and concrete shaft supported", IOSR Journal of Mechanical and Civil Engineering (IOSR-JMCE), 14(1), 2017, 38-46.

11. IS 1893 (Part-1) "Criteria for Earthquake Resistant Design of Structures", Bureau of Indian Standards, New Delhi, 2002.

12. S Nerkar. and C Nayak, "Seismic Behavior of Elevated Storage Reservoir by Finite Element Method", International Conference on Recent Innovation in Engineering and Management, 4(3), 2016, 1188-1197

\section{AUTHORS PROFILE}

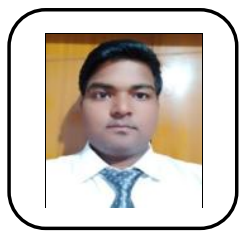

Mr. Rakesh Yadav: Author is presently working as an Assistant Professor in Department of Civil Engineering, Techno India NJR Institute of Technology, Udaipur since 2017. He has done his B.E and MTech from College of Technology and Engineering, Udaipur. His research area is Analysis \& Design of RCC and steel Structures and Concrete Technology. 
Seismic Behavior of RC Intze Water Tank under Various Zone and Soil Condition

Dr. Trilok Gupta: Author is currently working as an Assistant Professor in Department of Civil Engineering, MPUAT, Udaipur since 2007. His research area is Analysis \& Design of RCC and steel Structures and Concrete Technology.

Dr. Ravi K. Sharma: Author is currently working as Professor in Department of Civil Engineering, MPUAT,

Udaipur. His research area is Structural Analysis, Concrete Technology and Design of Concrete Structures 